\title{
TOWARD A THEORY OF THE ARTS AND SUSTAINABILITY
}

NANCY BERTAUX

(corresponding author)

Department of Economics

Xavier University

Cincinnati, Ohio, U.S.A.

bertaux@xavier.edu

KALEEL SKEIRIK

Department of Music

Xavier University

Cincinnati, Ohio, U.S.A.

skeirik@xavier.edu

Abstract. To make real progress on what can only be classified as environmental emergencies, we need a wide base of public consensus for action given that public motivation and involvement is a prerequisite for policymakers to implement what our scientists urge us to do. In this light, crucial thresholds of public motivation and involvement can be created by reaching into the hearts of individuals, an area of competitive advantage for the arts. Efforts to enhance understanding in this arena, however, must incorporate sufficient complexity given highly complex and inter-related challenges in sustainability. This article thus presents a theoretical framework for the arts and sustainability based on the variables of artistic complexity and public engagement. The arts, when allowed sufficient scope and freedom, can assist society in marshalling and galvanizing people across the globe to take essential steps toward a sustainable planet.

Keywords: arts and sustainability; complexity and sustainability; public engagement and sustainability 
Well, you've cracked the sky, scrapers fill the air.

But will you keep on building higher

'Til there's no more room up there?

... I know we've come a long way,

We're changing day to day,

But tell me, where do the children play?

— Cat Stevens, "Where Do The Children Play?" (1970)

\section{INTRODUCTION AND BACKGROUND}

We live in an era where sustainability is a topic we encounter at every turn. Our planet and its human inhabitants have begun to feel the complex effects of climate change, caused primarily by human activities with negative impacts that fall disproportionately on those least able to mitigate their effects (Stocker, 2014). As the result of heavy use of fossil fuel-based energy, agricultural methods that rely on deforestation, and a world economic system driven by ever-increasing consumption and waste of physical resources, we face enormous challenges in the supply of energy, water, renewable resources, and non-renewables such as minerals as well as with extensive and far-reaching environmental degradation like the acidification of our oceans and a dramatic loss of biodiversity (Winston \& Cupchik, 1992). We therefore outline in this study a powerful theory that addresses this challenge: the arts, through the empathetic process culturally embedded in each of the various types, communicate the real feeling, gravity, and complexity of the current problems the environment faces. Utilization of this fact will inform sustainability organizations that are working to heal the planet about the need to recognize and employ this powerful but little noticed cultural tool. Indeed, given the level of change required and the urgency associated with it - the global issues we face are so grave that the current century has been dubbed the "Environmental Century" (Mulkey, 2017) and the "Anthropocene" geologic age (Smith \& Zeder, 2013)—we need to add the role of culture and art to our sustainability toolkits.

The life-sustaining requirements of healthy integral ecological systems on Earth are as complex as the inter-relations of the current destructions, and changes advised as remedies for the situation are just as complicated. Such complexity, moreover, is more than our current media-driven world can deliver to the public, and whatever fragments of knowledge are broadcast come to be viewed by many as quagmires to be avoided or spurned. As a result, some still do not comprehend or 
accept the notion of limited or finite planetary resources; fewer still understand that waste products are threatening many of the Earth's species (including humans) well before we run out of resources, that "the sink will be full before the source is empty" (Daly \& Farley, 2011: 79). Thus, while the scientific consensus is quite clear (Stocker, 2014) and the public trusts scientists more than any other social institution to provide accurate information, there is still a large gap between scientists and the public in recognizing the seriousness of the challenges we face and the urgent need for significant changes in our systems (Pew Research Center, 2015, 2016). As such, we argue here that the empathy art evokes can help close this gap.

Indeed, there are too few of those who listen sufficiently to our scientists and thereby understand our sustainability challenges. As science historian Naomi Oreskes suggested, scientists need to learn better communication with the public, and the public at the same time must recognize when industry actors disseminate wrong or deceptive information disguised as science for their own profit (Oreskes, 2014; Oreskes \& Conway, 2011). Psychological and political factors also contribute to a lack of adequate public response to sustainability issues. For example, people may react with denial to reports on the severity of climate change, especially if it is perceived that personal sacrifices may be called for, and such reactions will also vary with individuals' political and economic identifications (Jylhä, Cantal, Akrami, \& Milfont, 2016). The arts, therefore, can play an important role by eliciting empathetic responses that will help individuals surmount such barriers.

There is also a growing sentiment among economic and business analysts at all levels-from local to global-that moving to a greener profile in all aspects of our society can and should provide fertile ground for increases in the quality, human satisfaction, viability, and indeed in the long-term profitability of our global and local economies (Hawken, Lovins, \& Lovins, 2010; Krugman, 2010; Melink, 2006; Whelan \& Fink, 2016). What these greener economies will look like, how democratic they will be, and how economic rewards will be distributed within them are all questions of great interest and debate (Morris \& Jungjohann, 2016; Rifkin, 2013, 2014; Shiva, 2005). The extent of public engagement with such inquiries will likely impact their outcomes to a great degree, and this will be affected in turn, as this article will argue, by how the arts become involved.

Once the public accepts the basic facts of global environmental crises, the issue of producing a workable understanding of their exceptionally complicated nature arises. The issues and challenges we confront are complex and interconnected, involving disparate areas of study 
concerning things like intricate and varied biological eco-systems; the health and interconnectedness of all the Earth's resources, water, air, soil, climate, plant and animal life; questions concerning the nature of human wants and desires; the life cycle of goods and services, including disposal/recycling or re-purposing; and how decisions are made and coordinated at all levels of society, from global to individual (Cain, 2014; Folke, 2016; Francis, 2015). As such, this article will also argue that the arts can enhance the public's ability to embrace and confront this complexity.

\section{MODEL AND DISCUSSION}

As we consider how the arts may contribute to positive public engagement with sustainable solutions to environmental challenges, it will be helpful to consider what we mean by "the arts." This term encompasses the performing arts (music, dance, theatre), visual/ conceptual arts (painting, sculpture, photography, architecture), and literary arts or literature (poetry, prose, and drama, as well as orally transmitted literature such as epics and myths) (The arts, n.d.). "Environmental art," then, is most often used as the umbrella term for visual and conceptual art related to the environment, although some use the term "eco-art" as the broadest category. Environmental art includes a wide variety of artistic forms, such as site-specific performance, ecopoetry, acoustic ecology, earthworks, eco-disco, bio-art, land art, eco-theatre, green activism, ecoventions, and many more (Bower, 2010; Environmental art, n.d.). It can be noted, however, that art by itself can also result in what some or even all would consider as "visual pollution," such as intrusive billboards or badly designed buildings. In this article, then, "artwork" refers to any type of art object, and, for simplicity, examples of artwork therein will be drawn largely from well-known pieces of music and visual art.

It will be instructive to describe two contrasting forms of environmental art by way of example. "Nature art," when defined as inspiring works of art with nature as subject, is perhaps the most basic and well-known form of environmental art. Examples include Ansel Adam's photographs of natural scenes, Mark Twain's descriptions of the Mississippi River in Huckleberry Finn, and Claude Monet's paintings of water lilies (another definition of nature art is art made from nature itself). The Nature Conservancy (The Nature Conservancy, n.d.) tells us that "nature is everywhere in art," and that by "conserving nature, we are helping nurture our artistic spirit." They make the link between 
nature art and environmental activism as follows: "The beauty of nature reflected in art is just another reminder of our need to protect it."

Pioneered by Joseph Beuys in the 1960s, "social sculpture" is a contrasting form of conceptual environmental art which includes human activity as well as elements of social or environmental change. An example of Beuys's innovative work dates from 1982 when he constructed a pile of stones on a German site-seen from the air, the pile showed itself to be an arrow pointing to an oak tree he planted. The project, which specified that to remove a stone one had to plant a tree where the stone was placed, resulted in 7,000 trees being planted in the area. Beuys's work thus demonstrates his contention that "every human being is an artist" while simultaneously and directly motivating individuals to take pro-environment actions (Environmental art, n.d.; Tate, n.d.).

\section{A. Art as Mover: Historic Precedents}

Art is for all, both artist and non-artist alike. Unbounded by the restrictions of language, at times partly or completely nonverbal, art "speaks" across cultures and time. People and societies recognize and understand the efficacy of art as a mover of the human heart, as the power within a culture to influence and change that culture one person at a time. Writers theorize on the subject while societies impose measures such as censorship laws or propaganda campaigns to control the influences of art upon the public (Perris, 1983). Art is powerful, and this makes it an excellent cultural tool to use at a time when our culture is so slow and reticent to implement new sustainable policies and actions. How can art be used? How does art relate to the complex issues of a full Earth? What can art provide that will be successful in the place of failed efforts from scientists, politicians, media experts, and others?

A few brief examples will illustrate these ideas. Plato, ever concerned about the requirements of civil society, suggested that only certain musical modes were acceptable to society because others were so powerful that they could lead to uncivil actions (D'Entremont, 1998). Viewing all forms of art as such a powerful part of society, Stalin's Soviet Union actively brought to the public only those works which supported socialist realism while artistic works deemed contradictory to it were aggressively censored (Dobrenko, 2007). The peaceful "Singing Revolution" of the 1980s that brought down the Iron Curtain in Estonia manifested the power of the arts to move people (Sky Films Inc., n.d.). Twelve cartoons of the Prophet Muhammad, published in a Danish newspaper in 2005, fomented a global political crisis; how this happened 
remains unexplained, yet the exceptional power of this art form to impact society is unquestionably clear (Müller \& Özcan, 2007). In the United States, the American Library Association regularly reports on banned and challenged books (ALA Office for Intellectual Freedom, n.d.).

This brief and varied list of examples demonstrates that art is an effective tool for activating awareness, action, and change. How then can organizations and our global society utilize artists and art to address the multitude of Earth stewardship concerns before us today? Such a question is centered on the creative process and its relationship to the public.

\section{B. The Creative Process and the Public}

The creative process means taking something that rises out of the subconscious and transforming it into intuitive content that the artist can articulate in some form (idea, sketch, concept, story, etc.). Intuition is then formulated into a mental construct before the artist finally combines these processes into a physical form, creating a piece of music, painting, sculpture, dance, book, etc. (Gilbert, 2015). The physical form of the artwork is what the audience interprets, and their interpretation theoretically contains all previous forms of the work plus any new content they impute from their life experiences. Ultimately, the audience takes complete ownership over their experience of the work of art.

Thus, in contrast to earlier criticism that tended to focus tightly on the artworks themselves, modern art and literary criticism suggest that multi-faceted components characterize interpretations (Suleiman $\&$ Crosman, 2014). Moreover, given that some of these interpretations exist outside the boundaries of the artwork itself, the experience of art is a contextual understanding developed by the audience/viewer/ participant and is not limited to any given work alone. This point as such is pivotal in explaining how art may be developed and used in our world to address sustainability concerns, which include a wide array of ideas that involve complex intersections of new knowledge with and against traditional values and the habits of old knowledge. "The vitality of audience-oriented criticism depends precisely on the realization that various dimensions of analysis or interpretation are possible, and that a combination of approaches is not a negative eclecticism but a positive necessity" (Suleiman \& Crosman, 2014: 7). In other words, the public experience or interpretation of an artwork is now understood as an integrated and expansive idea, and the original artwork comes to contain interpolations inserted by an individual or the public, depending upon context. 
The twelve cartoons of the Prophet Muhammad mentioned above are a case in point. Understanding art in this way creates connections of many types that extend far beyond a tightly restricted urtext (strictly based on the original) interpretation, and the expanded function this type of interpretation or criticism leads to extends the palette for the artist/audience experience. In this context, therefore, art is ripe for dealing with complex issues in society such as climate change. Several musical examples demonstrate the variety: many will be familiar with Joni Mitchell's "Big Yellow Taxi," a song that kicked off the environmental movement in the 1970s, or Macklemore's more recent rap about conspicuous consumption, "Wings" (2011) while other complex works such as three out of the last four Pulitzer Prizes in music show great concern for sustainability, specifically referencing climate change ("Become Ocean" by John Luther Adams, 2014), coal mining ("Anthracite Fields" by Julia Wolfe, 2015), and human trafficking ("Angel's Bone" by Du Yun, 2017).

All these pieces generate audience interpretations within the context of a "full" planet-an Earth with a human population and consumption patterns that exceed its sustainable support mechanisms (Daly, 2014). Although an artist like Beethoven wrote about nature in his Pastoral Symphony No. 6 , his music was experienced in a $19^{\text {th }}$ century context that stayed primarily within the boundaries of the work, closer to the naturalistic descriptions found therein. Beautiful and significant as it is in the history of music as a programmatic work, it can only speak historically; moreover, Beethoven's content voice has significantly weakened because it lacks the context of today's human-caused climate change destroying the very nature the symphony references (this does not of course preclude modern listeners from bringing today's context into play in their own individual interpretation of the work). By contrast, each of the recent Pulitzer Prize works cited above demands that audiences formulate a unique reaction and engagement with the challenges facing the Earth today and that they bring those into our culture. The interpretation will be properly eclectic, individual, and challenged by current practices across the globe.

\section{Empathy, Compassion, and Art}

We respond empathetically whenever we are actively engaged with an artwork. To develop a manageable model of art and sustainability, therefore, we must build a foundation upon the inherent capability of art to elicit empathetic and compassionate responses to the challenges we face in creating a sustainable world (Mace \& Ward, 2002). Scenes of suffering in films, for example, can cause us to feel pain. Music can easily trigger memories of a special time, a first experience, or of moments 
shared with a family member or friend; in fact, music perception studies repeatedly confirm that people can still identify basic and intended emotional cues and content that are consistent with the culture in which a piece of music was created-even if they are outside that culture's paradigm. Art, therefore, is especially powerful because it can activate the audience's capacity to experience emotion and feeling even when they are unfamiliar with the culture that produced the work.

Adam Smith, capitalism's first philosopher, acknowledged the key role of compassion and empathy (he calls the latter "sympathy") in the newly forming economic system based on competition and freetrade. He argued that the existence of sympathy as a basic human trait binds humanity together and leads to the creation of a "natural" moral order, which in turn allows a free enterprise system to function without disorder and social breakdown (Hanley, 2016). Smith carefully notes the key role of the human imagination:

As we have no immediate experience of what other men feel, we can form no idea of the manner in which they are affected, but by conceiving what we ourselves should feel in the like situation. Though our brother is on the rack, as long as we ourselves are at our ease, our senses will never inform us of what he suffers. They never did, and never can, carry us beyond our own person, and it is by the imagination only that we can form any conception of what are his sensations. Neither can that faculty help us to this any other way, than by representing to us what would be our own, if we were in his case. It is the impressions of our own senses only, not those of his, which our imaginations copy. By the imagination, we place ourselves in his situation. (Smith \& Haakonssen, 2002: 7)

Modern scholars have confirmed Smith's observation-based philosophy that we are neurologically hard wired to respond empathically (Rifkin, 2009). This fundamental human impulse to empathy/sympathy allows art, which also springs from the human imagination, to be an essential part of the equation for change. Art can succeed where science, the media, and politics alone fail precisely because art is empathetic within and across cultures, and when we experience an empathic feeling through art, we develop compassion that can lead to action. Art serves to activate this chain reaction, and its efficacy rests on our ability to engage our empathic selves with others toward sustainable change.

We have so far discussed how the arts can function in society as an effective cultural tool that dynamically engages people's hearts around an idea. To employ art successfully in this way, both the artist and those concerned with sustainable change need to be aware of art's key role in 
society and of the dynamics of art and complexity. The model below explores these dynamics.

\section{A Model of Complexity and Art}

Art holds the potential to mirror the complexity of a topic without being scientific, legalistic, or otherwise inaccessible to a wide audience due to technical or unfamiliar language. Art can also successfully communicate complex inter-relationships at the sub-conscious level since it enters the spirit and heart before reaching the mind. For example, it is well known that listening to music affects almost all limbic and para-limbic brain structures in contrast to the more focused structures affected by intellectual thought. Music therapists can therefore use the ability of music to evoke in reliable fashion exceptionally strong emotions that affect the mood of individuals (Koelsch, 2010). The field of advertising as well has long used the arts to influence human attitudes and behavior, at times even using challenging works and eliciting both positive and negative responses from critics (Tinic, 1997). Thus, given that affecting mood precedes content education, art represents a key opportunity for effectively managing the presentation of new and challenging content to the public. This in turn can be taken further with a focus on artistic complexity.

Figure 1 demonstrates the central focus of the theoretical argument in this article concerning the relation of art to sustainability: public engagement is understood to be a function of artistic complexity. The $\mathrm{x}$ axis represents the degree of complexity of a given artwork-increasing complexity means an increasing number of key artistic elements present in the work. Artistic complexity is thus an independent variable because the artist determines the number of elements in the artwork. The y axis represents the level of engagement experienced by the public audience, modeled here as the dependent variable. Art education studies clearly demonstrate how viewers are able to identify the elements or parts of an artwork, with even children clearly able to make such distinctions (Hardiman \& Zernich, 1982). It is thus reasonable to use this concept of the elements of an artwork in a model of sustainability and the arts. Accordingly, the higher the artistic complexity (the more elements an artist puts into play within the work), the higher the corresponding level of public engagement, resulting in an upward sloping function. ${ }^{1}$

${ }^{1}$ The authors plan to explore other aspects of this function in more detail in subsequent research. 
When the audience interprets a work of art, they experience it as a set of component elements or parts that they engage with and relate to in any way they choose. They are essentially selecting one or more combinations of the parts they have experienced to form their individual interpretation. Public engagement with art is thus defined as the rearranging of the parts of an artwork in a unique way that is meaningful to that individual. As such, when the artwork provides greater artistic complexity or more artistic component elements, it allows and indeed encourages higher levels of engagement on complicated issues (such as sustainability) and vice versa, so that a move toward less artistic complexity is associated, all things being equal, with a lower potential to engage complex understanding.

\section{Engagement of Public vs. Artistic Complexity}

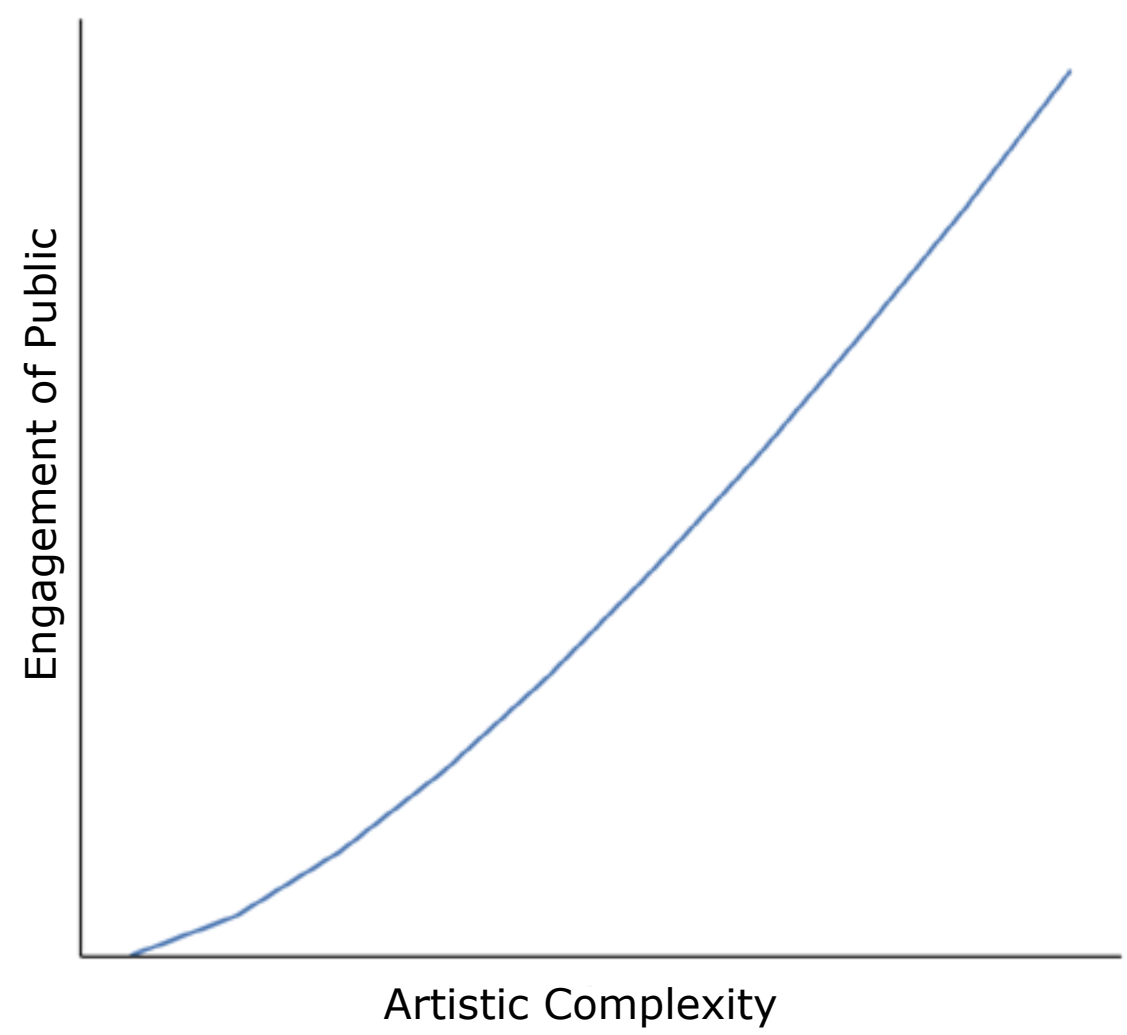

Figure 1: Engagement of Public vs. Artistic Complexity

Understanding the complexity-engagement relationship is important when considering how culture helps increase awareness about complex 
issues in sustainability. An artwork that adds complexity in relating to an ecological topic mirrors the complexity of the topic or issue itself and produces new opportunities and paths for audience engagement. This expanded opportunity to appreciate and accept the complex topic increases in turn the ways in which the artwork may enter the heart. Thus, compared to a scientific journal article which would always take complexity into account but which could fail to communicate its main concept to the public for reasons of jargon and elaborate intellectual content, a topical artwork that incorporates elements of this scientific complexity may have a better chance of engaging the public and eventually preparing it to deal with the outcomes related to a given article. In short, well-crafted art with a slightly higher degree of complexity holds strong promise for communicating with audiences and engaging them on complex issues in sustainability, and yet this remains an unexploited asset.

Of special importance, however, is art that currently exhibits very low levels of complexity but involves large markets, such as commercial and popular arts. These forms of art are potentially powerful precisely because of the wide audience to which they have access, and, as discussed below, they sometimes address sustainability directly and intentionally to communicate basic concepts such as the benefits of recycling or energy conservation or the ill effects of pollution. The influence of these arts on sustainability is faltering, however, because of the singular and simplified focus typically employed in commercial applications, which in turn is due to the perception that audiences respond better to simple messages and stimuli (Schmidt, 1990).

\section{E. Categories of Artistic Complexity}

Figure 2 below attempts to examine levels of artistic complexity and public engagement more closely by modelling five broad categories of art in regions along the curve. In order of increasing complexity, these are commercial and popular arts, ${ }^{2}$ transitional arts (a fusion of commercial/popular arts and the classical arts), classical arts, and the serious contemporary arts. Such categories, though they may not be appropriate for every work, account for much of the art experienced in our culture today. The overlaps between categories are important as well, indicating ambiguity as to where each begins and ends. The graph is thus intended to locate and explain different types of art for the purpose of connecting art to the public, especially when that art involves content, ideas, or purposes related to sustainability.

${ }^{2}$ The question of whether commercial art in particular is indeed "art" is a longstanding debate beyond the scope of this article. For the purposes of this study, it is assumed to be a simple art form (Schmidt, 1990). 
Commercial and Popular Arts are characterized primarily by the fact that they have a very high level of interaction with the public either through use or purchase. The Transition Arts cover a wide region between the Popular Arts and the Classical Arts, and have selected characteristics from both categories. The Classical Arts tend to be mostly of historic interest, and are primarily shared with the public through subsidized venues such as libraries, art galleries, classical music series, etc. The Serious Contemporary Arts occupy a region the public is much less aware of; for the most part, this art is complex, intended to be highly engaging, and created mostly during our lifetimes, often using contemporary or avant-garde techniques (Bertaux, Skeirik, \& Yi, 2015). Of special interest in this article will be the region of lowest complexity, Commercial and Popular Arts, which is omnipresent in modern culture and yet yields relatively lower engagement for the audience.

Levels of Complexity \& Artistic Categories:

Engagement of Public vs. Artistic Complexity

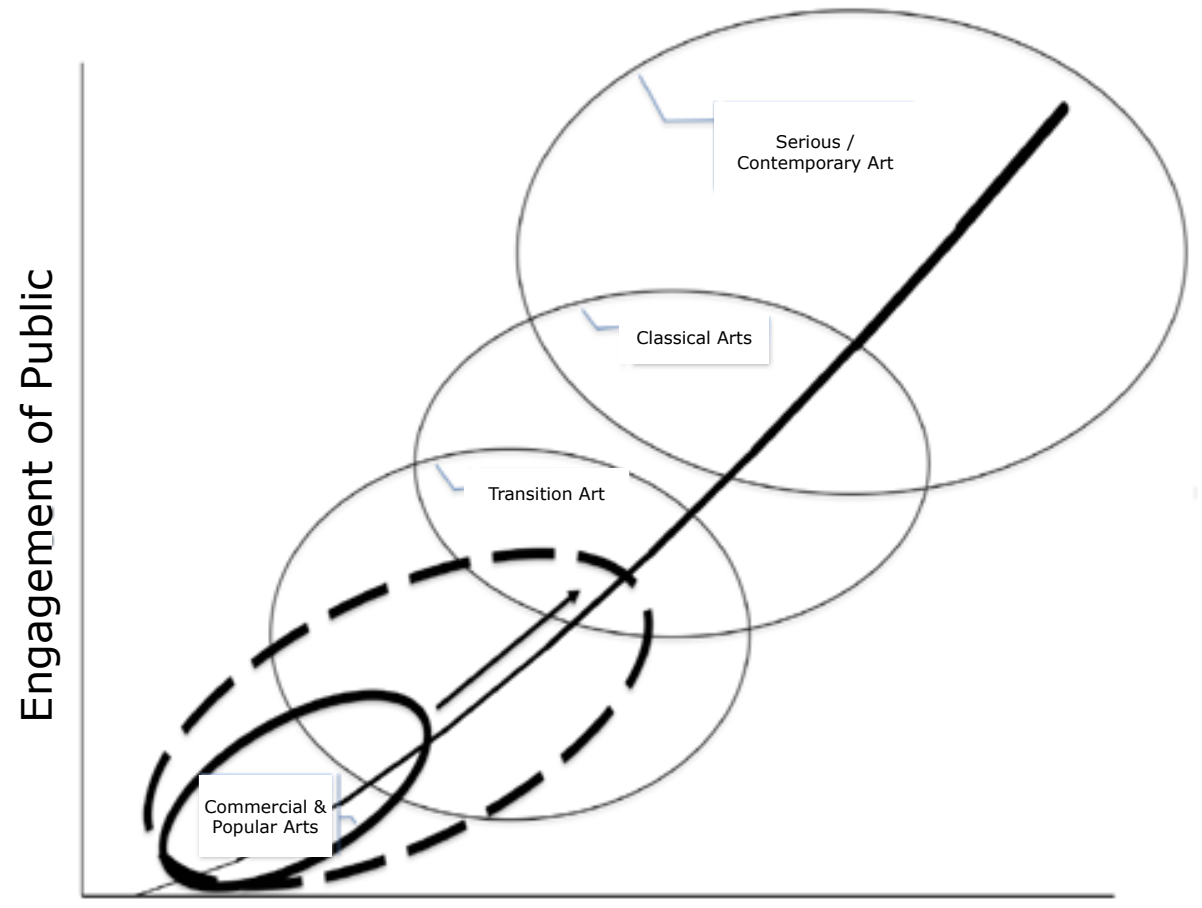

Artistic Complexity

Figure 2: Levels of Complexity \& Artistic Categories: Engagement of Public vs. Artistic Complexity 
An exit sign is an example of commercial art and the Beatles song "I Want to Hold Your Hand" (1963) is an example of popular art. Representing functional art for business purposes, the exit sign involves a single, basic artistic element and a correspondingly simple level of engagement. The Beatles song would sit to the right of the exit sign and has several elements such as text, rhythm, and harmony, and thus a higher degree of complexity.

Complexity increases and the general style becomes more involved as we move into transition arts, with terms such as "fusion" sometimes characterizing these works (Sutton, 2008). Wynton Marsalis exemplifies a cross-over artist who in 1983 won Grammy awards in both classical and jazz. Andy Warhol's “Campbell's Soup Cans" (1962) exactly replicates the labels on said soup cans, manifesting a low level of complexity from that point of view; however, when the 32 large images of cans are considered as a whole, his piece exhibits a higher degree of complexity, thereby causing more challenging engagements with viewers.

Classical Art is well known to symphony and art museum patrons as well as to readers of serious literature, poetry, and other historic arts. Examples would range from ancient Greek sculptures to symphonic literature for the orchestra and to works such as those of the poet Walt Whitman. These pieces are viewed today as cultural milestones for their times, are more extensive, have many component parts, and often demonstrate techniques novel to their era.

Finally, Serious Contemporary Art is intellectually involved contemporary art with many inter-related elements. Contemporary in this context is interpreted as being within an artist's lifetime (Bertaux et al., 2015), although works of a simpler nature, such as renditions of the Star Wars theme by a pops orchestra, are not included. The Serious Contemporary region occasionally exhibits popular and commercial interests, however, such as the modal pulse music of Steve Reich (b. 1939-) or the surrealistic paintings of Salvador Dali (1904-1989).

As observed above, the increasing prevalence of commercial and popular art in our global society can potentially be used to influence sustainability awareness, commitment, and understanding in a positive way. Indeed, the addition of even one or two elements in a commercial or popular artwork can significantly increase its engagement factor with an audience and, ultimately, its impact on sustainability. The dotted oval and associated arrow in Figure 2 thus show the proposed expansion of the range of complexity exhibited in the Commercial and Popular Arts to increase its overlap with Transition Art. Simple popular constructions need additional complexity to allow the public to select the meanings 
and ideas that appeal to their hearts, which results in more effective communication about the complexities of ecological economies, new sustainability programs, and integral ecologies. ${ }^{3}$

The model presented above thus informs the artist and sustainability implementer that when the level of complexity installed in an artwork comes close to mirroring the level of complexity inherent in a sustainability topic, the potential for true and constructive societal engagement can increase, and perhaps exponentially.

\section{IMPLICATIONS}

An obvious implication of this model concerns the importance of artistic freedom since art cannot flourish without it. This article suggests that freedom of artistic expression is a crucial foundation for mobilizing the arts in the service of sustainability. Establishing and encouraging freedom for the arts, however, presents varied challenges for different nations and cultures (Harris, 2005; Johnson \& Canaves, 2009; Kearns, 2013; Okeke-Agulu, 2010).

Society also needs to go beyond ensuring artistic freedom to provide room for a movement toward greater complexity, and so a further concern of this article involves the tendency of commercial interests to influence the arts toward less complexity (Collins \& Skover, 2005). Commercially successful pop music, for example, is generally simple in structure, based on tried and true forms, and singular in message (Starr $\&$ Waterman, 2008). Moreover, a review of today's top ten popular songs reveals the content of the lyrics to be primarily about sex, with the top five focused exclusively on this topic (Billboard, n.d.; Rasel, 2017). There is no environmental content in any of the top ten songs, and so while pop music pieces on environmental themes do exist, the more complex messages they contain typically receive much smaller public exposure and less commercial success. A society that bathes in an ocean of commercial and popular arts, with infrequent visits to small ponds of more complex arts, therefore risks losing one of its primary tools of societal awareness. As such, there is an urgent need in most global societies for increased public access to a wide variety of artworks found across the spectrums of type and complexity. This in turn suggests a further need for increased public support for the arts (Cherbo \& Wyszomirski, 2000) to ensure a vibrant artistic community for sustainability managers and activists to interact with and use as inspiration.

${ }^{3}$ See Pope Francis's call for "integral ecology" in his 2015 encyclical Laudato si'. 
A compassionate public, one that engages in complexity through sensitive artworks, can truly innovate and create new economies for an integral ecology because it has a rich vein out of which creative new thinking may flow. Out of these arts will come the inspiration and revitalized commitment to build a full Earth and a new world, for art is the affecting force needed to stimulate true intellectual knowledge and invention-it is not knowledge itself but the force behind knowledge. Few other aspects of society glare into the mirror and deliver this affect, no matter how beautiful or upsetting it may be. Indeed, science has begun to recognize that it cannot solve this problem alone, that it needs the arts to deliver empathy. Ecologist Gerardo Ceballos observes, for example, that the "massive loss of populations and species reflects our lack of empathy to all the wild species that have been our companions since our origins" (Phillips, 2017).

\section{CONCLUSION}

Creativity through the arts is an essential cultural tool that society harnesses to activate compassion and engagement (Kagan, 2014). When a human person's heart is moved, the wildest, strongest horse in the corral is saddled. It is ironic, then, that human creativity enabled the economic growth that has generated our complex environmental degradations, for it is creativity and compassion that must drive solutions found both within and beyond these problems. As such, below are a few applied examples in art, business, government, and the public sector of how a deep recognition of complexity in sustainability and environmental issues can increase public engagement toward more effective solutions.

- Businesses, advertisers, and business educators can utilize the guidelines in the sustainability communications toolkit of the United Nations Environment Programme (UNEP). Following these guidelines will increase the complexity level of advertising and thereby more successfully engage the public with product and environmental realities while mutually benefiting both (United Nations Environment Programme, n.d.).

- Expand the National Endowment for the Arts to combine more applied sustainability/environmental art with shovel-ready public/business projects that are receiving federal funding. Coupling projects and funds will increase awareness and appropriately move art projects up the complexity curve, thereby increasing public engagement. 
- Established arts organizations can adjust their missions to set aside a third of their commissioning funds for sustainability/environmental topics of local or regional interest, thereby employing place-based engagement goals that connect with local audiences.

- Sustainability and environmental organizations, such as the Environmental Defense Fund or the Sierra Club, could initiate and develop a cultural/artistic arm for the specific purpose of increasing engagement through artistic works, one that is consistent with current projects and goals.

- Businesses can begin considering "managing for sustainability" by becoming aware of artistic statements that have been created relative to their specialties, and with a view toward unique solutions that would not have been available to the organization without the artistic engagement factor. Such engagement can be seen as analogous to diversity/inclusion training which, when done well, results in "managing for diversity" (Chavez \& Weisinger, 2008).

- Billboard should recognize the number and significance of environmental songs in popular music with a new category called "Earth Music" (not to be lumped in with the Social Chart), thereby stimulating more popular interest in sustainability.

For art to speak effectively of the truth and beauty that we are seeking, sustainability leaders and environmentalists can utilize the following ideas:

- we are the first generation to face these unknowns;

- our economies must be understood as existing within the larger sphere of nature;

- morality is the foundation for economic and social structures;

- compassion and empathy, including compassion for the Earth, are effective and natural tools for moving the hearts of human persons;

- the arts are society's oldest means of delivering emotive material, pre-dating modern social and economic structures (White, 2003); and 
- the arts, at the requisite level of complexity, can engage people to care of and solve these unknowns.

Free artistic expression and sufficiently complex artistic works can move us to understanding and action for a more humane and sustainable world. As stated at the recent Jesuit task force on ecology (which served as a key input to Francis's Laudato Si'), we "need to confront our inner resistances and cast a grateful look on creation, letting our heart be touched by its wounded reality and making a strong personal and communal commitment to healing it" (Álvarex, 2011: 7). This "look on creation" can and should include artistic visions that are creative, uncensored, and richly reflective of the underlying complexity in our world's eco-systems and challenges. Once we know what we are looking for, then and only then can we effect change. Art indeed is the catalyst that activates the empathetic vision within the heart.

To summarize, we clearly require wide consensus on the need for timely and significant action to make real progress with what can only be classified as environmental emergencies. This consensus, however, will not arise from sound, well-replicated scientific studies alone, for while scientific analysis and understanding necessarily form the foundation of our actions, many other hands are needed on deck. When we look to our policymakers, whether at the local, regional, national, or international level, we find a remarkable inability to take successful and meaningful steps (Lefalle, 2008). Even a highly lauded and hard-won measure such as the Paris climate accord, for example, is currently undergoing setbacks because of politicians' varied agendas (Shear, 2017). It is highly likely then that the public at large needs to be motivated and involved as a prerequisite for policymakers to be so. The focus of this article, therefore, has been on adding another complementary factor to this process, namely, the importance of reaching into the heart of every individual, which is an area of competitive advantage for the arts. ${ }^{4}$ It is the thesis of this study that the arts are a prime candidate for creating crucial thresholds of empathy, motivation, and involvement in the public. When allowed sufficient freedom and scope, the arts can greatly assist society in better marshalling and galvanizing people across the globe to take essential steps toward a sustainable planet.

${ }^{4}$ This change of heart may also occur through faith and spirituality; see Francis, for example, on the need for a change of heart to re-think fundamentally about behaviors and practices so that we may preserve our Earth and the life on it, both human and otherwise (Francis, 2015: § 218). 


\section{REFERENCES}

ALA Office for Intellectual Freedom. (n.d.). 2015 Book challenges infographic. Available at http://www.ala.org/bbooks/frequentlychallengedbooks/statistics (accessed July 5, 2017).

Álvarex, P. (Ed.). 2011. Healing a broken world: Task force on ecology. Promotio Iustitia, No. 106, 2011/2. Available at http://www.sjweb.info/documents/sjs/ pjnew/PJ106ENG.pdf.

Bertaux, N., Skeirik, K., \& Yi, D. 2015. Art music and the economy: The modernity index and the Cincinnati Symphony Orchestra, 1895 to 2013. International Journal of Economics and Business Research, 9(4): 376-392.

Billboard. (n.d.). The hot 100. Available at http://www.billboard.com/charts/hot-100 (accessed July 14, 2017).

Bower, S. 2010. A profusion of terms. Available at http://www.greenmuseum.org/ generic_content.php?ct_id=306.

Cain, M. L. 2014. Ecology. Sunderland, MA: Sinauer.

Chavez, C., \& Weisinger, J. 2008. Beyond diversity training: A social infusion for cultural inclusion. Human Resource Management, 47(2): 331-350.

Cherbo, J. M., \& Wyszomirski, M. J. 2000. The public life of the arts in America. New Brunswick, NJ: Rutgers University Press.

Collins, R. K. L., \& Skover, D. M. 2005. The death of discourse. Durham, NC: Carolina Academic Press.

D'Entremont, J. 1998. The devil's disciples. Index on Censorship, 27: 32-39.

Daly, H. 2014. From uneconomic growth to a steady-state economy. Cheltenham, UK / Northampton, MA: Edward Elgar Publishing.

Daly, H. E., \& Farley, J. C. 2011. Ecological economics: Principles and applications. Washington, DC: Island Press.

Dobrenko, E. A. 2007. Political economy of socialist realism. New Haven, CT: Yale University Press.

Environmental art. (n.d.). Wikipedia: The free encyclopedia. Wikimedia Foundation Inc. Available at https://en.wikipedia.org/wiki/Environmental_art.

Folke, C. 2016. Resilience (republished). Ecology \& Society, 21(4): 656-685.

Francis. 2015. Laudato si': On care for our common home. Huntington, IN: Our Sunday Visitor.

Gilbert, E. 2015. Big magic: Creative living beyond fear. New York: Riverhead Books. Hanley, R. P. 2016. Adam Smith: His life, thought, and legacy. Princeton, NJ: Princeton University Press.

Hardiman, G. W., \& Zernich, T. 1982. The relative influence of parts and wholes in shaping preference responses to paintings. Studies in Art Education, 23(3): 31-38. DOI: https://doi.org/10.2307/1320014.

Harris, K. 2005. Artistic freedom and social responsibility. Report of the Aspen Institute Roundtable on Leadership and the Media. Washington, DC: Aspen Institute Communications and Society Program. 
Hawken, P., Lovins, A. B., \& Lovins, L. H. 2010. Natural capitalism: The next industrial revolution. London/Washington, DC: Earthscan.

Johnson, I., \& Canaves, S. 2009. Artists test limits as China lets (a few) flowers bloom. Wall Street Journal-Eastern Edition, 254(78): A1-A20.

Jylhä, K. M., Cantal, C., Akrami, N., \& Milfont, T. L. 2016. Denial of anthropogenic climate change: Social dominance orientation helps explain the conservative male effect in Brazil and Sweden. Personality and Individual Differences, 98: 184-187. https://doi.org/10.1016/j.paid.2016.04.020.

Kagan, S. 2014. Art and sustainability: Connecting patterns for a culture of complexity. Transcript Verlag. Available at https://books.google.com/ books?id=3bHWBQAAQBAJ.

Kearns, P. 2013. Freedom of artistic expression: Essays on culture and legal censure. Oxford, UK / Portland, OR: Hart Publishing.

Koelsch, S. 2010. Towards a neural basis of music-evoked emotions. Trends in Cognitive Sciences, 14(3): 131-137. https://doi.org/10.1016/j.tics.2010.01.002.

Krugman, P. 2010. Building a green economy. The New York Times Magazine, 5(April 7): 2-16.

Lefalle, P. F. 2008. Beyond science: Climate change as a perfect political dilemma. Political Science, 60(1): 9-18.

Mace, M.-A., \& Ward, T. 2002. Modeling the creative process: A grounded theory analysis of creativity in the domain of art making. Creativity Research Journal, 14(2): 179-192. https://doi.org/10.1207/S15326934CRJ1402_5.

Melink, S. 2006. One firm's journey to LEED gold and green living. Heating/Piping/ Air Conditioning Engineering, 78(9): 50-54.

Morris, C., \& Jungjohann, A. 2016. Energy democracy: Germany's Energiewende to renewables. Cham Springer International Publishing Imprint. Palgrave Macmillan.

Mulkey, S. 2017. Higher education in the environmental century. The American Journal of Economics and Sociology, 76(3): 697-730.

Müller, M. G., \& Özcan, E. 2007. The political iconography of Muhammad cartoons: Understanding cultural conflict and political action. PS: Political Science \& Politics, 40(2): 287-291. https://doi.org/10.1017/S104909650707045X.

Okeke-Agulu, C. 2010. The art society and the making of postcolonial modernism in Nigeria. South Atlantic Quarterly, 109(3): 505-527.

Oreskes, N. 2014. Why we should trust scientists. TED: Ideas worth Spreading. Available at https://www.ted.com/talks/naomi_oreskes_why_we_should_ believe_in_science (accessed February 1, 2018).

Oreskes, N., \& Conway, E. 2011. Merchants of doubt: How a handful of scientists obscured the truth on issues from tobacco smoke to global warming. New York: Bloomsbury.

Perris, A. 1983. Music as propaganda: Art at the command of doctrine in the People's Republic of China. Ethnomusicology, 27(1): 1-28. DOI: 10.2307/850880.

Pew Research Center. 2015. Public and scientists' views on science and society. Available at http://assets.pewresearch.org/wp-content/uploads/sites/14/2015/01/ PI_ScienceandSociety_Report_012915.pdf. 
Pew Research Center. 2016. The politics of climate. Available at http:// assets.pewresearch.org/wp-content/uploads/sites/14/2016/10/14080900/ PS_2016.10.04_Politics-of-Climate_FINAL.pdf.

Phillips, K. 2017. Earth is on its way to the biggest mass extinction since the dinosaurs, scientists warn. The Washington Post. Available at https://www. washingtonpost.com/news/speaking-of-science/wp/2017/07/12/earth-is-on-itsway-to-the-biggest-mass-extinction-since-the-dinosaurs-scientists-warn/.

Rasel. 2017. Rasel-Despacito (videoclip oficial). YouTube. Available at https://www. youtube.com/watch?v=WGc86H4PvEg.

Rifkin, J. 2009. The empathic civilization: The race to global consciousness in a world in crisis. New York: J. P. Tarcher/Penguin.

Rifkin, J. 2013. The third industrial revolution: How lateral power is transforming energy, the economy, and the world. New York: Palgrave Macmillan.

Rifkin, J. 2014. The zero marginal cost society: The internet of things, the collaborative commons, and the eclipse of capitalism. New York: Palgrave Macmillan.

Schmidt, S. J. 1990. What advertising can tell scholars of empirical aesthetics. Poetics, 19(4): 389-404.

Shear, M. 2017. Trump will withdraw U.S. from Paris climate agreement. The New York Times, June 1. Available at https://www.nytimes.com/2017/06/01/climate/ trump-paris-climate-agreement.html?action=click\&contentCollection=Europe $\&$ module $=$ RelatedCoverage\&region=Marginalia\&pgtype $=$ article .

Shiva, V. 2005. Earth democracy: Justice, sustainability, and peace. Cambridge, MA: South End Press.

Sky Films Inc. (n.d.). The singing revolution. Available at https://singingrevolution. com/ (accessed July 5, 2017).

Smith, A., \& Haakonssen, K. 2002. Adam Smith: The theory of moral sentiments. Cambridge, UK: Cambridge University Press.

Smith, B. D., \& Zeder, M. A. 2013. The onset of the Anthropocene. Anthropocene, 4: 8-13.

Starr, L., \& Waterman, C. A. 2008. American popular music. Washington, DC: U.S. Dept. of State, Bureau of International Information Programs.

Stevens, C. 1970. Where do the children play? Island Records/A\&M Records. Lyrics available at http://www.metrolyrics.com/where-do-the-children-play-lyrics-catstevens.html (accessed July 12, 2017).

Stocker, T. 2014. Climate change 2013: The physical science basis. Working Group I contribution to the fifth assessment report of the Intergovernmental Panel on Climate Change. New York: Cambridge University Press.

Suleiman, S. R., \& Crosman, I. 2014. The reader in the text: Essays on audience and interpretation. Princeton, NJ: Princeton University Press.

Sutton, R. A. 2008. What's that sound? Korean fusion music and the ascendancy of the "Haegŭm." Asian Music, 39(2): 1-27.

Tate. (n.d.). Social sculpture. Available at http://www.tate.org.uk/art/art-terms/s/ social-sculpture.

The arts. (n.d). Encyclopaedia Britannica. Available at https://www.britannica. com/topic/the-arts. 
The Nature Conservancy. (n.d.). The nature of art. Available at https://www.nature. org/ourinitiatives/regions/northamerica/unitedstates/nevada/placesweprotect/ the-nature-of-art.xml (accessed February 1, 2018).

Tinic, S. A. 1997. United colors and untied meanings: Benetton and the commodification of social issues. Journal of Communication, 47(3): 3-25. https://doi.org/10.1111/j.1460-2466.1997.tb02714.x.

United Nations Environment Programme. (n.d.). Sustainability communications: A toolkit for marketing and advertising courses. Available at http://www.unep. fr/shared/publications/pdf/DTIx0886xPA-EducationKitEN.pdf.

Whelan, T., \& Fink, C. 2016. The comprehensive business case for sustainability. Harvard Business Review Digital Articles, 2-8.

White, R. 2003. The prehistoric art: The symbolic journey of humankind. New York: Harry N. Abrams.

Winston, A. S., \& Cupchik, G. C. 1992. The evaluation of high art and popular art by naive and experienced viewers. Visual Arts Research, 18(1): 1-14. 